\title{
OS MITOS SOBRE O OZÔNIO: UM RESGATE DAS ORIGENS DA DISCUSSÃO - II
}

Ricardo Augusto Felicio ${ }^{1}$

RESUMO: Em 1987, implementou-se o Protocolo de Montreal que baniu gradativamente o uso das famílias dos gases CFCs, obrigando o mundo a substituí-lo por outras famílias de gases, bastante similares, conhecidos por HCFCs. A troca atingiu uma escala sem precedentes, pois todos os equipamentos que usavam os gases anteriores, altamente inertes e estáveis, tiveram também que serem substituídos, o que causou um prejuízo imenso à empresas, com altos custos transferidos à população mundial, tanto financeiros, quanto de saúde e bem-estar. O presente trabalho foi dividido em duas partes, sendo que esta segunda e última parte apresentou os desdobramentos e problemas referentes a esta substituição em larga escala, bem como os problemas que a envolveram. Também apresentou evidências que discutem os supostos danos da radiação ultravioleta $B$. Discutiu-se o quão problemática é a manutenção de uma burocracia eternizada pelo "Painel do Ozônio", que agora elenca uma nova substituição dos gases HCFCs, mantendo seu domínio em criar procedimentos que dificultam o crescimento das sociedades emergentes, minando a segurança dos processos produtivos e de conservação de alimentos e remédios. Em meio a tantas fraudes científicas sobre 0 assunto, sua burocracia internacional institucionalizada e sabendo-se de todas as benfeitorias que os compostos conhecidos como CFCs trouxeram para os humanos, só nos resta realizar a campanha: que os CFCs sejam declarados patrimônio da humanidade, com retomada total de seu uso.

Palavras-chave: Mudanças Climáticas. Ozônio. Mitos.

${ }^{1}$ Prof. Dr. Climatologista, Departamento de Geografia - USP. ricaftnt@yahoo.com. 


\section{INTRODUÇÃO}

No primeiro volume deste artigo, recordou-se toda a história sobre o gás ozônio $\left(\mathrm{O}_{3}\right)$, desde os anos de 1970 até o banimento dos compostos conhecidos como CFCs. Explicou-se a formação do ozônio na estratosfera, relembrando que o mesmo só surge com a radiação solar, especificamente como produto da fotodissociação da radiação ultravioleta da banda $\mathrm{C}$, UV-C com o gás oxigênio $\left(\mathrm{O}_{2}\right)$.

Neste segundo volume, demonstrou-se os aspectos políticos e econômicos, os quais causaram grandes problemas para diversos setores, das mais variadas atividades humanas. Também verificou-se que, uma vez criada tal burocracia internacional, acordada por regulamentos, as dificuldades em se negociar qualquer coisa que seja, ficam sujeitas à aprovação de comitês, que cobram exigências de metas sobre o tema para aprovação de outros assuntos, alheios ao mesmo. Criou-se um sistema coercivo de negociação internacional que faz frente aos assuntos geopolíticos e de relações internacionais. Vale lembrar que tudo isto foi criado porque um fenômeno natural foi transformado em uma falsa emergência global.

\section{OBJETIVOS}

Apresentar, neste segundo e último volume, uma discussão sobre todos os problemas que foram gerados pela proibição gradativa da produção dos compostos organofluorados, desde a substituição de máquinas e equipamentos até os reflexos causados para o combate a incêndios, aplicações na indústria farmacêutica e o paradoxo biológico da incidência de radiação ultravioleta. Também apresentou-se uma crítica ao "painel do ozônio" e suas revisões periódicas, as quais incluem novos produtos, toda vez que acham necessário substitui-los por outros modernos da indústria química mundial.

Pretende-se também demonstrar os efeitos nefastos da burocracia internacional institucionalizada nos países emergentes como China, Índia e principalmente Brasil no que tange a nova substituição programada, que consumirão recursos financeiros extremados, conta paga justamente por aqueles que são os mais carentes. 


\section{MATERIAL E MÉTODOS}

A pesquisa permaneceu sobre os textos e livros citados em bibliografia dos anos de 1990 até as atuais, preferencialmente os estrangeiros. Também utilizou-se de reportes da mídia nacional e internacional para demonstrar os desdobramentos políticos e econômicos, norteados pela burocracia internacional do "painel do ozônio", o qual continua a impor suas mazelas aos países, com amplos reflexos aos mais subdesenvolvidos, ou que apresentam uma evolutiva política de desenvolvimento, como é o caso do Brasil.

As conclusões de ambos os volumes permitirão verificar que os compostos CFCs deveriam retornar a produção mundial, sem ônus algum, pois tratam-se de substâncias altamente eficientes e úteis, não correndo risco ambiental algum.

\section{DISCUSSÃO DOS ELEMENTOS}

\subsection{O Painel do Ozônio e o Protocolo de Montreal}

Em 1987 foi instituído o primeiro painel "científico" mundial: o International Ozone Trends Panel - IOTP, ou Painel Internacional da Tendência do Ozônio, o qual visou resolver um problema que vimos, inexistente (FELICIO e ONÇA, 2012). Restou agora entender o que motivou esta intrincada cadeia de acontecimentos que misturam ciência com política.

Deliberadamente, um plano foi traçado, inclusive observando que os países subdesenvolvidos como Brasil, China e Índia estavam passando, na década de 1980, por um crescimento significativo do setor de refrigeração. Ao mesmo tempo, em pelo menos dois deles, Brasil e Índia, boa parte dos seus territórios encontram-se em áreas quentes e tropicais. Conservar comida é uma necessidade básica que estava se expandindo para as pessoas mais necessitadas, com queda de preços dos produtos de refrigeração e

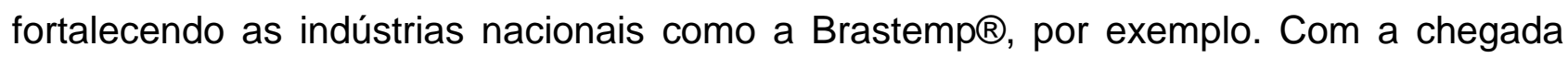


dos anos de 1980, a perda das patentes dos gases CFCs, de uso em grande escala, derrubariam os preços de vários destes gases para apenas US $\$ 1,38$ o quilograma. Assim, com os trabalhos já iniciados em 1977, o Protocolo de Montreal tomou vulto dez anos depois, em 1987, com a formação do IOTP (ou simplesmente OTP). Deve-se recordar também que antes as patentes duravam 50 anos. Hoje, cerca de 20 anos.

Tudo isto não ocorreu sem uma ampla divulgação de condenação dos gases CFCs da indústria de refrigeração, realizadas por ONGs internacionais que recebiam, curiosamente, financiamento de várias das empresas as quais detiam as patentes das famílias de gases CFCs. Além destas, as fundações filantrópicas da elite financeira, como Rockefeller, Ford, MacArthur, entre outras, ajudaram no propósito de banir os CFCs e cortar os processos de refrigeração, impondo a ideologia malthusiana, que considera que o mundo precisa de menos pessoas. O financiamento destas instituições na condenação dos CFCs somou mais de 500 milhões de dólares, em valores de 1990 (MADURO e SCHAUERHAMMER, 1992).

Poucos sabem que os gases CFCs foram, de certa forma, "criados", para resolver problemas específicos da indústria. Até por volta de 1930, eram usados como fluidos refrigerantes principalmente a amônia $\left(\mathrm{NH}_{3}\right)$, o butano $\left(\mathrm{C}_{4} \mathrm{H}_{10}\right)$, o isobutano $\left[\mathrm{HC}\left(\mathrm{CH}_{3}\right)_{3}\right]$, o propano $\left(\mathrm{C}_{3} \mathrm{H}_{8}\right)$, o dióxido de enxofre $\left(\mathrm{SO}_{2}\right)$ e o cloreto de metil $\left(\mathrm{CH}_{3} \mathrm{Cl}\right)$. Contudo, como são substâncias tóxicas e/ou explosivas, podendo colocar em risco a vida humana em caso de vazamento, foram abandonadas, exceto em algumas aplicações mais ou menos especializadas. Muitos acidentes na parte industrial ocorreram nas operações com estes antigos gases. Em geral, foram substituídas pelos CFCs. A amônia, em particular, sendo o fluido de maior efeito refrigerante, continuou sendo utilizada em instalações de grande porte como fábricas de gelo, armazéns frigoríficos, equipamentos de refrigeração industrial e em pistas de patinação, onde conta o fator energético e onde podem ser implementados procedimentos de segurança.

Além de equipamentos de refrigeração, os CFCs passaram a ser usados em aparelhos condicionadores de ar, em borrifadores (sprays), na fabricação de espuma de poliestireno (isopor $\left.{ }^{\circledR}\right)$ e em uma série de outros produtos. Em especial, por serem compostos orgânicos, cujas moléculas contêm carbono e flúor e, em muitos casos, outros halogêneos, principalmente o cloro, alguns CFCs se apresentavam no estado líquido ou 
gasoso, a temperatura ambiente. Não eram tóxicos, além de incolores, inodoros, não inflamáveis e não corrosivos. Alguns dos CFCs mais usados foram os compostos R11 Freon-11® $\left(\mathrm{CCl}_{3} \mathrm{~F}\right), \mathrm{R} 12$ - Freon-12® $\left(\mathrm{CCl}_{2} \mathrm{~F}_{2}\right)$, R22 $\left(\mathrm{CHClF}_{2}\right)$ e R502 (mistura de $48,8 \%$ de $\mathrm{CHClF}_{2}$ com $51,2 \%$ de $\mathrm{C}_{2} \mathrm{ClF}_{5}$ ), entre outros da extensa família de gases.

Não obstante, houve uma verdadeira batalha de discussões pelo mundo a fora, principalmente nos EUA, mesmo este já tendo abolido o uso de diversos CFCs, a implementação disto pelo Protocolo de Montreal, em caráter mundial, foi amplamente discutido, embora nada disto tenha chegado ao Brasil, a não ser a "evidência" de morte, mudança e de futuro duvidoso da humanidade, "frente a maior ameaça que ela já se deparara" (que com a chegada do fim da Guerra Fria, deixara de ser a guerra termonuclear global). As discussões tomavam rumos dos mais esquisitos e irracionais, ao ponto de se realizarem comparações esdrúxulas de Marte com a Terra, inclusive de renomados cientistas como Carl Sagan, que embora tenha se mantido equilibrado nas discussões, teve o disparate de dizer que os efeitos na Terra seriam idênticos aos de Marte, caso o ozônio desaparecesse, pois a superfície de Marte é castigada pela ação da radiação ultravioleta (SAGAN, 1998). Ora, isto é um absurdo! Marte possui uma atmosfera extremamente tênue, com cerca de apenas 6,8 a 10,8mb de pressão atmosférica em superfície (registros da Viking I e II) enquanto que a Terra tem 1013,25mb ao Nível Médio do Mar. Ademais, o ozônio é um gás transiente formado pela radiação UV C sobre o gás oxigênio. Assim, em Marte, é a ausência de uma atmosfera significativa, a qual não seleciona os feixes eletromagnéticos da radiação, que permite que a superfície receba uma incidência intensa de radiação, inclusive UV C. A Terra nunca seria assim! Vale lembrar que Sagan, bem como Paul J. Crutzen, Richard Turco e outros proponentes da hipótese do "Inverno Nuclear", realizaram simulações para tal situação em modelos de computador. Estas simulações depois foram completamente descartadas porque estes cientistas não levaram em conta, convenientemente, a ação dos oceanos, que cobrem quase $3 / 4$ da superfície terrestre. $O$ modelo ainda descartou propositalmente efeitos de trovoadas, ciclones tropicais e todas as interações Ar-Mar, sem falar ainda das erupções vulcânicas. Sagan mesmo admitiu depois, gradualmente, que seu modelo não foi concebido para realizar ciência, mas sim, política, objetivando interferir estrategicamente nos rumos da Guerra Fria, os quais foram muito bem aproveitados pela indústria do 
cinema de Hollywood, como o filme The Day After, no Brasil, "O Dia Seguinte" (MEYER, 1983). Stephen Schneider ainda tentou "salvar" a hipótese, lançando a idéia de "outono nuclear" que depois foi esquecida. Sobre tudo isto que ocorreu na época, o físico Freeman Dyson sugeriu uma simples fórmula para a questão do inverno nuclear: "Boa Política, Péssima Física".

Desta forma, estabeleceu-se o palco para a criação de uma crise mundial ambiental, sem proporções, vendendo o medo do câncer e a extinção das espécies, inclusa aí a do próprio Homem. Maurice Strong, antes de terminar a sua gestão à frente do Programa das Nações Unidas para o Meio Ambiente - PNUMA, em 1975, já deixou tudo muito bem esquematizado para o fechamento do acordo do Protocolo de Montreal, que como informado, vai se firmar de 1987 a 1990, entrando em pleno vigor em 1989 e que até o ano de 1991, conseguiu a chancela de quase a totalidade dos países do mundo (de fato, até 2007, apenas três países africanos não o assinaram, o que não fazia nenhuma diferença dada a sua falta de industrialização). Quanto à formação do OTP, entre os seus primeiros 21 membros estavam inclusos, como presidente, Robert $\mathrm{T}$. Watson, vice-presidente, Richard Turco, inventor da "teoria do inverno nuclear". Entre os participantes dos chamados "grupos de trabalho" estavam Harold Johnston, inventor da "teoria dos óxidos nitrosos que destroem ozônio", Richard Stolarski, inventor da "teoria do cloro dos ônibus espaciais e que seus foguetes destroem ozônio", Rumen Bojkov, Ivar Isaksen, Ralph J. Cicerone, Michael McElroy. Em especial Susan Solomon, que nunca realizou um trabalho de campo, mas lançou 33 balões ao lado do vulcão antártico, monte Erebus, e é, claro, Sherwood Rowland e Mario Molina, autores da hipótese fraudulenta da depleção do ozônio. A única coisa que estes cientistas têm em comum é que suas reputações foram impostas para "provar" a hipótese. Parafraseando Maduro e Schauerhammer, a raposa foi designada para vigiar o galinheiro, fato muito comum na mesma questão que envolve as "mudanças climáticas" e "aquecimento global" atuais, principalmente no que tange ao Brasil, incluindo o destino de fábulas em recursos, nunca auditados.

4.2 Revisões do Protocolo de Montreal e as Mazelas Impostas 
Até o presente momento, o documento recebeu cinco revisões, demonstrando que tais burocracias ficam eternizadas dentro do sistema econômico (LINO et al. 2007). Surpreendentemente, em uma delas, até mesmo o brometo de metila, passou a ser proibido pelo Protocolo de Montreal, fazendo os países mais subdesenvolvidos, por não terem mais direito a usar este poderoso gás fulmígeno, a perderem grandes quantidades de grãos colhidos por causa do ataque de fungos, insetos, vermes, roedores e outras pragas (FERREYRA, 2006).

Em uma das revisões realizadas em 1991, o modus operandi foi o mesmo realizado em 1988. Watson, presidindo o OTP, apresentou o "Sumário Executivo" dos resultados, que segundo ele, foram retirados de um relatório de 300 páginas a ser lançado pelo PNUMA ("Sumário Executivo" pode ser entendido como um resumo de um suposto relatório grande e completo). No entanto, tal relatório nunca existiu, segundo o porta-voz do próprio PNUMA. A conferência de imprensa do PNUMA foi seguida por audiências no Congresso Estadunidense em 15 de novembro de 1991, presidido pelo então senador Albert Gore, o qual tentava, em explanação, vincular a disseminação da AIDS e da artrite à destruição do ozônio (MADURO e SCHAUERHAMMER, 1992).

A patifaria deste artifício burocrático não termina aí. Desde o princípio ele objetivou realizar a quebra da conservação de alimentos no mundo tropical pobre. $\mathrm{O}$ próprio Sherwood declarou que sabia que as conseqüências do "Painel de Ozônio" e seu Protocolo de Montreal seriam nefastas e milhões de pessoas morreriam por envenenamento de comida, mas eram perfeitamente justificáveis, por causa de um bem maior: "salvar a Terra!". Assim, muito pior que o custo da substituição dos CFCs é o custo das vidas humanas. Só para se ter uma idéia, em 1990, cerca de $75 \%$ dos alimentos nos EUA em algum momento passaram pela refrigeração por CFCs. No mundo este valor vinha crescendo significativamente. Assim, a proibição dos CFCs significou que centenas de milhões de refrigeradores tiveram que ser demolidos. A conseqüência desta situação foi um colapso da capacidade de armazenamento de alimentos em todo o mundo e um aumento dramático na taxa de morte por fome e doenças de origem alimentar, como botulismo e salmonelas. As estimativas na época eram de 20 a 40 milhões de pessoas por ano, como resultado da proibição direta do uso dos CFCs, já que estes números eram aceitos como gerados pelos problemas de má conservação alimentar (FERREYRA, 
2006). O Prof. Kaminski, do Instituto de Agricultura e Economia Alimentar, em Varsóvia, Polônia, reportou, em 1988, na Conferência Internacional de Refrigeração, em Paris:

Refrigeração, desde que seja aplicada em uma complexa e bem organizada cadeia de resfriamento, pode, em grande parte, contribuir para o aumento e salvaguarda dos recursos mundiais de alimentos, garantindo uma importante diminuição nas perdas quantitativas e qualitativas dos alimentos produzidos, desde a colheita da matéria-prima, até o consumo do produto acabado (KAMINSKI, 1988).

Além dos problemas de comida, também não se pode esquecer das aplicações na medicina destes gases. Resfriamento de sangue e plasma também entraram no cômputo deste problema, dificultando a fabricação e obtenção de equipamentos de produção específica de refrigeração para estes propósitos. Os ambientalistas defensores do banimento dos CFCs também esqueceram propositalmente de citar que tais gases eram usados em todos os dispositivos de pressão que realizavam a aplicação de remédios em asmáticos (as famosas bombinhas portáteis). Por serem gases completamente inertes, não eram absorvidos pelos pulmões, mas serviam de veículo para pressionar as substâncias medicinais diretamente nos alvéolos pulmonares, realizando uma melhor performance da pressão positiva sobre eles, em cada aspirada do paciente.

De certo, os CFCs, principalmente os Halons, salvaram a vida de milhares de pessoas todos os anos. Além dos aspectos de sua aplicação na medicina, os Halons que continham bromo na sua composição, possuíam a extraordinária capacidade de extinguir incêndios e suprimir explosões. Afortunadamente, os Halons não são tóxicos, não são corrosivos e principalmente, não causam danos à equipamentos elétricos e eletrônicos. Sua toxidade é tão baixa, que é possível aplicá-lo em um incêndio furioso, sem colocar em risco as pessoas presentes. O dióxido de carbono, entretanto, é também efetivo em combater incêndios, mas sufoca pessoas e animais, além de operar em uma temperatura extremamente baixa. Outros equipamentos de combate à incêndios, como os derivados da técnica PQS - Pó Químico Seco, extinguem incêndios sem prejudicar as pessoas, mas acabam danificando equipamentos de eletrônica e informática.

O Chemetron Fire System (ou Sistema de Incêndio Chemetron) foi criado para combater incêndios em áreas confinadas ou de alto risco. Ele usava Halon-1301®, um 
dos gases da família CFCs. A sua eficiência foi comprovada em diversos experimentos científicos e militares, inclusive salvando vidas em centros de computação, salas de controle de caldeiras e gás, interior de aviões em vôo, submarinos, praças de máquinas etc. O gatilho de alta precisão em disparo e o sistema de alta pressão de Halon tinham o poder de não somente extinguir o fogo, mas de exterminar o chamado fireball, ou bola de fogo, da explosão inicial, que ocorre por exemplo, no alcance do ponto de fulgor de um material, em ambiente que rapidamente a mistura do combustível e comburente se tornam suficientes para se desencadear o fogo expansivo. A capacidade do Halon, lançado por sistemas espargidores, suprimia o fireball em 1/4 de segundo, não deixando sequer que o fogo conseguisse queimar a pele dos operadores de salas sinópticas de situação de fábricas, controle de caldeiras etc. Estima-se que a inexistência destes sistemas tão eficientes, ceifem cerca de mil vidas por ano.

Aos poucos, o Protocolo de Montreal foi encerrando todo o tipo de produção dos CFCs na quase totalidade do mundo, sendo que estes extintores de incêndio Halon, específicos para as classes $\mathrm{D}$ e E, utilizados para aplicação em combate à incêndios em praça de máquinas de navios e uso no interior de aviões, bem como fogos derivados de materiais de magnésio, ainda ficaram até 2007. A Du Pont foi oferecendo outros gases como o Halon-1211® e HFC-123®, mas estes provaram serem incapazes de parar incêndios, não sendo possível substituir a eficiência do Halon-1301® (o Novec1230® é o substituto da Chemetron que usa o HFC-123®). Só mesmo quem vivenciou estas situações sabe o valor e a importância de se possuir esta arma de combate aos fogos citados acima. A remoção destes do quadro operacional de combate ao fogo só elencou aos seus participantes, a categoria de maiores patifes da humanidade, sem pestanejar. A muitos deles, só restou cair no esquecimento, pois a partir do ponto em que o Establishment oligárquico internacional conseguiu os seus propósitos, houve um repentino desinteresse sobre o estado da "camada de ozônio", abandonando a mídia e ficando "fora de moda" do ano de 2000 até aproximadamente 2008, sendo o assunto pouco abordado pelo PNUMA, IPCC, OMM e ONGs em geral. O decréscimo das pesquisas foi evidente, pois não havia mais verbas. Internacionalmente desvendou-se quem eram as fontes de recursos e verbas: as próprias empresas químicas já citadas. No Brasil, a FAPESP tomou esta incumbência, inclusive demonstrando, com orgulho, em 
relatório recente, ter sido a financiadora de vanguarda nas pesquisas sobre 0 assunto, bem como mitigando agora os formidáveis e fabulosos recursos para outra pseudociência, a do "aquecimento global antropogênico". Dentro destas pesquisas, curiosamente, também nunca explicaram por que o tal "buraco" só ocorria na Antártida, sendo que os maiores emissores de CFCs eram os países do hemisfério Norte. Na tentativa de se corrigir esta "falha", alguns trabalhos ainda foram posto em discussão, como o mais recente, onde uma equipe enorme de pesquisadores declaram uma perda de ozônio "sem precedentes" no Ártico, em 2011 (MANNEY et al., 2011). Claro que sempre houve anomalias do ozônio sobre o Ártico também e isto era sabido desde o século XIX. A pesquisa ainda relatou que a anomalia de 220 a 230UD ocorreu no final do mês de março, diametralmente oposta, em todos os sentidos, ao que ocorre na Antártida, mas é claro, no mesmo período equivalente. No hemisfério Sul, a saída do inverno com a chegada da primavera ocorre em setembro. O mesmo período, no hemisfério Norte, ocorre em março.

Deixa-se de citar ainda neste capítulo o uso do Metil Clorofórmio e do Tetracloreto de Carbono, cujas aplicações estão em todos os produtos modernos, principalmente na eletrônica. Também não se citou a especial capacidade do Hexafluoreto de Enxofre, um gás que tem a propriedade de ser um refrigerante poderoso, aliada à capacidade de isolamento elétrico. Sua principal aplicação é refrigerar e isolar os barramentos trifásicos elétricos entre o estator e os transformadores das usinas hidrelétricas gigantes, como a bi-nacional Itaipú. Ele fica no interior da tubulação que envolve os barramentos. Assim, todas estas substâncias foram vitimadas e controladas pelo Protocolo de Montreal.

\subsection{Burocracia e Poder Internacionalizado sem Evidências Científicas}

Diferentemente de outros acordos internacionais, o Protocolo de Montreal criou coercivamente datas-limite para o completo encerramento do uso das famílias de CFCs, além de permitir que outras substâncias pudessem ser removidas da produção industrial, ao bel-prazer de um grupo de "cientistas" do OTP, a qualquer momento, já que esta burocracia teima em não terminar. 
Segundo as declarações do diplomata Richard Benedick, pró-Montreal, em seu livro Ozone Diplomacy: New Directions in Safeguarding the Planet, ou Diplomacia no Ozônio, Novas Direções na Salvaguarda do Planeta, de 1991, temos:

O Protocolo de Montreal... determinou significativas reduções no uso de vários produtos químicos extremamente úteis... Pela sua ação, os países signatários assinaram a sentença de morte para uma importante parte da indústria química internacional, com implicações de bilhões de dólares em investimentos e centenas de milhares de empregos em setores correlatos. O protocolo, simplesmente, não prescreveu limites para esses produtos com base na 'melhor tecnologia disponível', que teria sido a maneira tradicional de reconciliar objetivos ambientais com os interesses econômicos. Em vez disto, os negociadores estabeleceram datas-limite para a substituição de produtos que haviam se tornado sinônimos de padrões de vida modernos, ainda que as tecnologias requisitadas ainda não existissem. (LINO et al., 2007, p.15)

Antes de ser destacado para as negociações do Protocolo de Montreal, Richard Benedick chefiou o Gabinete de População do Departamento de Estado, nos EUA, onde sempre defendeu as aplicações coercivas de controle da população em países subdesenvolvidos. Assim, dificultar a refrigeração doméstica nos países de terceiro mundo, quando sua maior parte está na área tropical, significa diretamente prejudicar a conservação de alimentos. Melhor ainda se for possível destruir as indústrias nacionais que se apontavam como pontos de liderança na produção em seus países. Assim, durante a época da instituição das ações governamentais, ele mesmo admitiu:

$\mathrm{Na}$ época das negociações e da assinatura, não existia nenhuma evidência de problemas mensuráveis. Assim, ao contrário de acordos ambientais do passado, o tratado não foi uma resposta a acontecimentos ou eventos prejudiciais, mas uma ação preventiva em escala global. (LINO et al., 2007, p.16)

Notemos que 'não existia nenhuma evidência de problemas mensuráveis', que significou exatamente o que foi exposto até o presente momento, e de tudo que afirmaram diversos cientistas mundiais compilados aqui e em outros artigos: nunca houve de fato uma prova, uma evidência de que os CFCs "destruíam" ozônio". Eles no máximo mostraram que existia cloro na atmosfera e estratosfera. Nunca mostraram as origens deste cloro. Deste modo, quando o presidente da Du Pont fez a afirmação de que $95 \%$ do 
cloro na atmosfera era de origem antrópica, não passou de mera especulação. Aliás, especulação esta que rendeu milhões de dólares para as respectivas indústrias detentoras das patentes destes gases, como a própria Du Pont, ICl, Atochem, Allied Chemicals e a Hoechst, esta última, que patrocinou o programa Globo Ecologia, da Rede Globo de televisão, por anos e anos, com o intuito de difamar os CFCs sem trégua (quem não se lembra: "Globo Ecologia, um oferecimento: Hoechst, química à serviço da vida!").

\subsection{Trocando e Combatendo os CFCs para Implementar os HCFCs}

Os principais fabricantes internacionais de CFCs foram pouco afetados pela substituição dos produtos. A indústria química possuía um trunfo embaixo da manga: os hidrofluorcarbonos (HFCs) ou também os hidroclorofluorcarbonos (HCFCs). A indústria, na época, informava que eles também seriam "danosos à camada de ozônio", porém de uma forma menor. Curiosa foi a "quantificação" deste processo de periculosidade, que não passou de outra mera suposição. O Protocolo de Montreal criou o absurdo índice ODP - Ozone Depleting Potential, ou Potencial de Depleção do Ozônio, que quanto mais próximo de zero, melhor (curiosamente, a turma "aquecimentista" do IPCC já criou algo semelhante, o índice GWP - Global Warming Potential, ou Potencial de Aquecimento Global). O importante foi que os objetivos foram atingidos. Ao se substituir os gases antigos, que não pagavam mais patentes, por outros, cujo preço na época subiu mais de 30 vezes, com alguns HCFCs, como o R134, custando US $\$ 38,00$ o quilograma, em relação aos CFCs que chegaram a menos de dois dólares a mesma quantidade, as empresas como a Du Pont e a $\mathrm{ICl}$ engordaram substancialmente seus lucros e hegemonia mundial em pelo menos dez bilhões de dólares (em 1993). Ao mesmo tempo, os gases novos não funcionavam eficientemente nos aparelhos antigos, exigindo então a substituição de todos os equipamentos. Não é de se surpreender que se criou um mercado negro para o uso dos CFCs, dado o preço extorsivo dos seus substitutos, de maneira que só nos EUA, uma estrutura especial de polícia, a qual só perdia para o combate ao narcotráfico, foi elaborada com a finalidade de criar uma repressão policial ao uso das substâncias mais úteis e de grande aplicabilidade já verificadas (LINO et al., 2007). 
Ademais, a Du Pont e a $I C I$ trabalharam juntas na questão dos CFCs. Eles mantiveram uma frente comum em termos de política, mas a ação mais importante foi a criação de instalações de produção conjunta de HFC-134a e outros produtos químicos de reposição patenteados para CFCs. Além disso, Du Pont e a $\mathrm{ICI}$ formaram e lideram uma organização internacional em forma de consórcio que passou a testar as alternativas aos CFCs. Tal arranjo, que costumava ser ilegal, permitiu habilitar estas empresas em criar os seus substitutos para os CFCs para o mercado, muito mais rapidamente do que a concorrência.

Assim, com o chancelamento da "ciência" de Molina, agraciado com um prêmio Nobel de Química pelo "salvamento da humanidade", uma imensa onda de recursos financeiros foram liberados para difamar os CFCs em todas as escalas e aplicações possíveis, não importando se eram laboratoriais ou se nunca seriam possíveis de ocorrer no mundo real, como mostrar malefícios em plantas e animais, com doses absurdas de UV B (FERREYRA, 2006). O Brasil também não ficou de fora desta história. Dentro das "pesquisas" e da opinião científica para legitimar o desuso dos CFCs, o INPE - Instituto Nacional de Pesquisas Espaciais teve papel crucial, na figura do alemão naturalizado brasileiro, Volker Kirchhoff, que levou com maestria tal processo, incluindo projetos na Antártida, na localização da Estação Antártica Comandante Ferraz - EACF do Brasil, onde mediram as concentrações de ozônio pela inferência da radiação UV B. Claramente suas pesquisas mostrariam o que sempre se soube: que o ozônio varia muito na Antártida, sendo que isto não prova nada sobre cloro, CFCs entre outras aberrações (Fig.4.4.1). Como únicas vozes contrárias na época no Brasil, tivemos o Prof. Dr. Molion, climatologista brasileiro, e o geólogo Geraldo Lino, do MSla - Movimento de Solidariedade Ibero-americana. Este último participou de debates homéricos com Kirchhoff, com trocas de artigos escritos no Jornal do Brasil, incluindo programas de rádio no estado do Rio de Janeiro. É claro que, como Kirchhoff não venceu nos argumentos científicos, a sua posição, como outros, é de sempre atacar vigorosamente seus adversários com contos mais esdrúxulos possíveis. Além disto, Kirchhoff ainda apelou para o principal argumento atual da ciência: o da autoridade, a dele, é claro, tratando as vozes dissidentes apenas como de "leigos intrometidos", mas deixando os argumentos 
destes "leigos" sem a réplica, aliás, hábito bastante comum na pseudociência climática atual.

Ainda nos anos de 1990, o Prof. Dr. Molion, escreveu uma carta ao então presidente da República, Fernando Collor de Mello (de 1990 a 1992) para que este não assinasse o Protocolo de Montreal, pois isto seria o fim da indústria de refrigeração brasileira. A carta foi interceptada pelo então Secretário do Meio Ambiente, o físico José Goldemberg, conhecido ativista ambiental internacional que simplesmente não apresentou o documento de alerta à presidência. Deve-se ainda relatar um breve histórico de Goldemberg como chefe da Fundação Gaia no Brasil, financiada pelo governo britânico. Ele foi premiado pelo Right Livelihood da Fundação Gaia por sua "visão e trabalho individual, contribuindo para tornar a vida mais íntegra, curando o nosso planeta e edificando a humanidade". No júri internacional de sua premiação estavam presentes Rodrigo Carazo, ex-presidente da Costa Rica, fundador e presidente da Universidade da Paz das Nações Unidas, Monika Griefahn, Greenpeace, e Robert Muller, exSubsecretário-Geral das Nações Unidas e um importante colaborador internacional do Lucis Trust, uma organização da elite neo-Satânica que opera o Templo do Entendimento na ONU e de muitos fundos de grupos ambientalistas (A Lucis Trust foi originalmente chamado de Lucifer Trust, mas seu nome foi mudado depois de protestos nas Nações Unidas de diversas nações católicas). Goldemberg foi o principal agente organizador da Cúpula da Terra, de 1992, realizada no Brasil (MADURO e SCHAUERHAMMER, 1992). Em janeiro de 2013 recebeu outro prêmio, mais um "reconhecimento internacional". Foi agraciado com o Prêmio Zayed de Energia do Futuro (Zayed Future Energy Prize) na categoria Life Achievement, concedido a profissionais de destaque na área de energia renovável, outra mazela imposta à humanidade. Seu prêmio de meio milhão de dólares foi dado em cerimônia na capital dos Emirados Árabes Unidos (JORNAL DA USP, 2013), coincidentemente, um dos países que mantém um status de apenas "aceitação" do Protocolo de Montreal, enquanto que a Arábia Saudita, por exemplo, simplesmente abandonou o tratado (atualmente, 11 países deixaram o Protocolo de Montreal). 


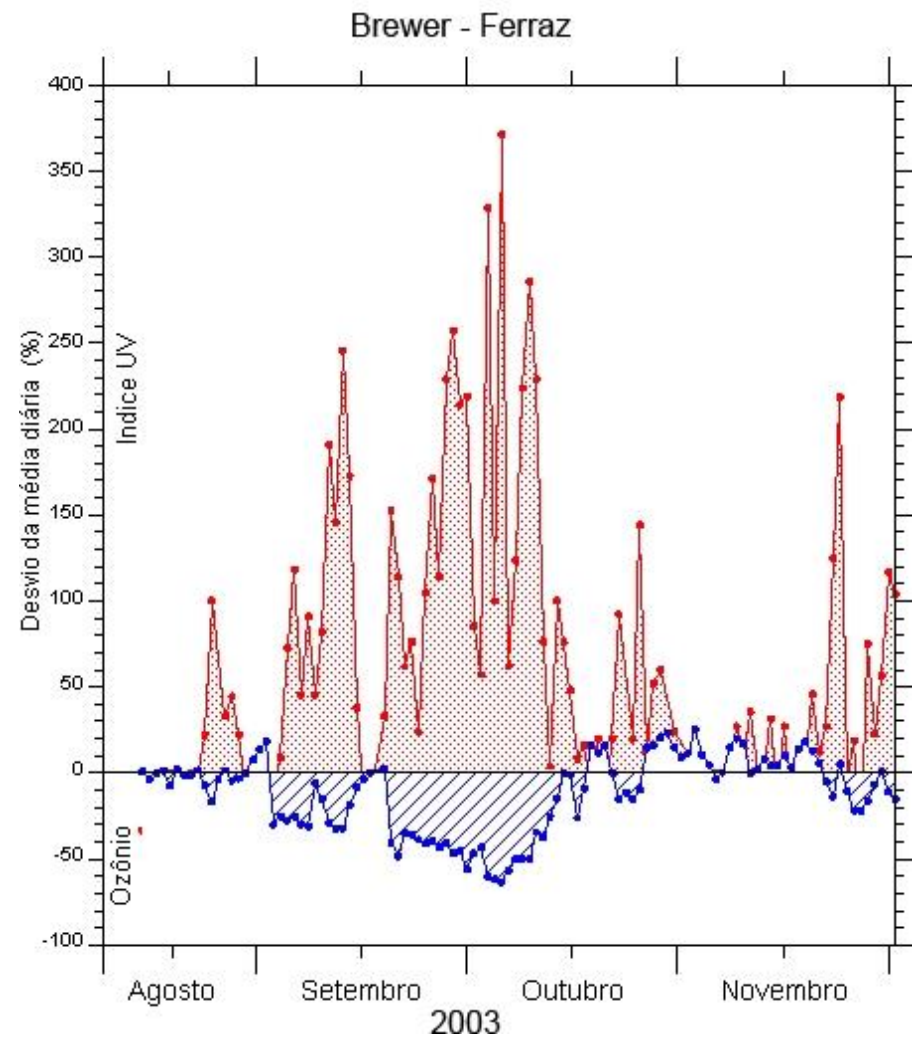

Fig.4.4.1: Gráfico do desvio da média diária da incidência da radiação UV B e a produção de ozônio, obtidas na Estação Antártica Comandante Ferraz, em 2003 de agosto a novembro. O Próprio Dobson relatou, em 1957, que medir ozônio era espantoso. A variação pode ser maior que 1000\% (Fonte: INPE, 2003).

Retomando o raciocínio temporal, a crise financeira em que se encetava o Brasil no começo dos anos de 1990, criou uma situação bastante constrangedora, pois o FMI utilizou do argumento ambiental para liberar recursos aos países que o necessitavam. Assim, quem não assinava o Protocolo de Montreal não recebia ajuda financeira do FMI. Artigos de notícias relatando sobre a Conferência de junho de 1990, em Londres, alegavam que os representantes das 59 nações que ratificaram o tratado assinaram porque foram convencidos da "evidência científica" apresentada na conferência. Isso não poderia estar mais longe da verdade. A maioria dos países que assinaram o tratado o fizeram porque tinham uma arma apontada para suas cabeças. Há uma cláusula no Protocolo de Montreal, que obriga a manter um estado de guerra econômica contra qualquer nação que não participar. O artigo $4^{\circ}$ do tratado, intitulado "Controle de Comércio com Não-Partes", descreve, em detalhes, as ações que seriam tomadas contra os países que não assinassem o protocolo. Os mandatos da cláusula das nações 
signatárias iriam impor uma embargo comercial total contra qualquer nação do mundo que não cumprisse o Protocolo de Montreal. Nações signatárias estão proibidas de exportar estas "substâncias controladas" a qualquer nação que não assinar o protocolo. Diante de uma cláusula assassina como esta, a maioria das nações não tiveram outra alternativa senão assinar o tratado.

Esta é uma questão do que tem sido chamado de apartheid tecnológico. Em março de 1989, porta-vozes de várias empresas químicas de porte anunciaram que a construção de fábricas de produtos químicos para a produção de CFCs no Terceiro Mundo tinha sido interrompida, e os contratos existentes para construir as fábricas de CFC, não seriam mais honrados! A nova política foi exportar CFCs para essas nações durante alguns anos até a "eliminação". Quanto aos Países do Terceiro Mundo seria apenas permitido comprar os caros substitutos HCFCs e os novos equipamentos necessários para usá-los. Assim, o que vemos é a imposição de um totalitarismo e imperialismo, costurado por um acordo ambiental completamente sem propósito. A prova disto está no próprio sítio da Internet do OTP, onde constatou-se que os EUA, Holanda, Espanha e Grécia tem autorização de produzir CFCs para mercado interno e para exportar para o resto do mundo para "suprir suas necessidades básicas". Ao mesmo tempo, outros países, quentes e/ou tropicais, podem comprar os CFCs dos produtores que foram celebrados pelo tratado, mantendo um mercado cativo por imposição, sob produtos que não precisariam mais pagar patentes. Esta que é a grande questão e que poucos entendem: uma aplicação direta do esquema Cap-And-Trade, Limitar-e-Comercializar (Fig.4.4.2). 

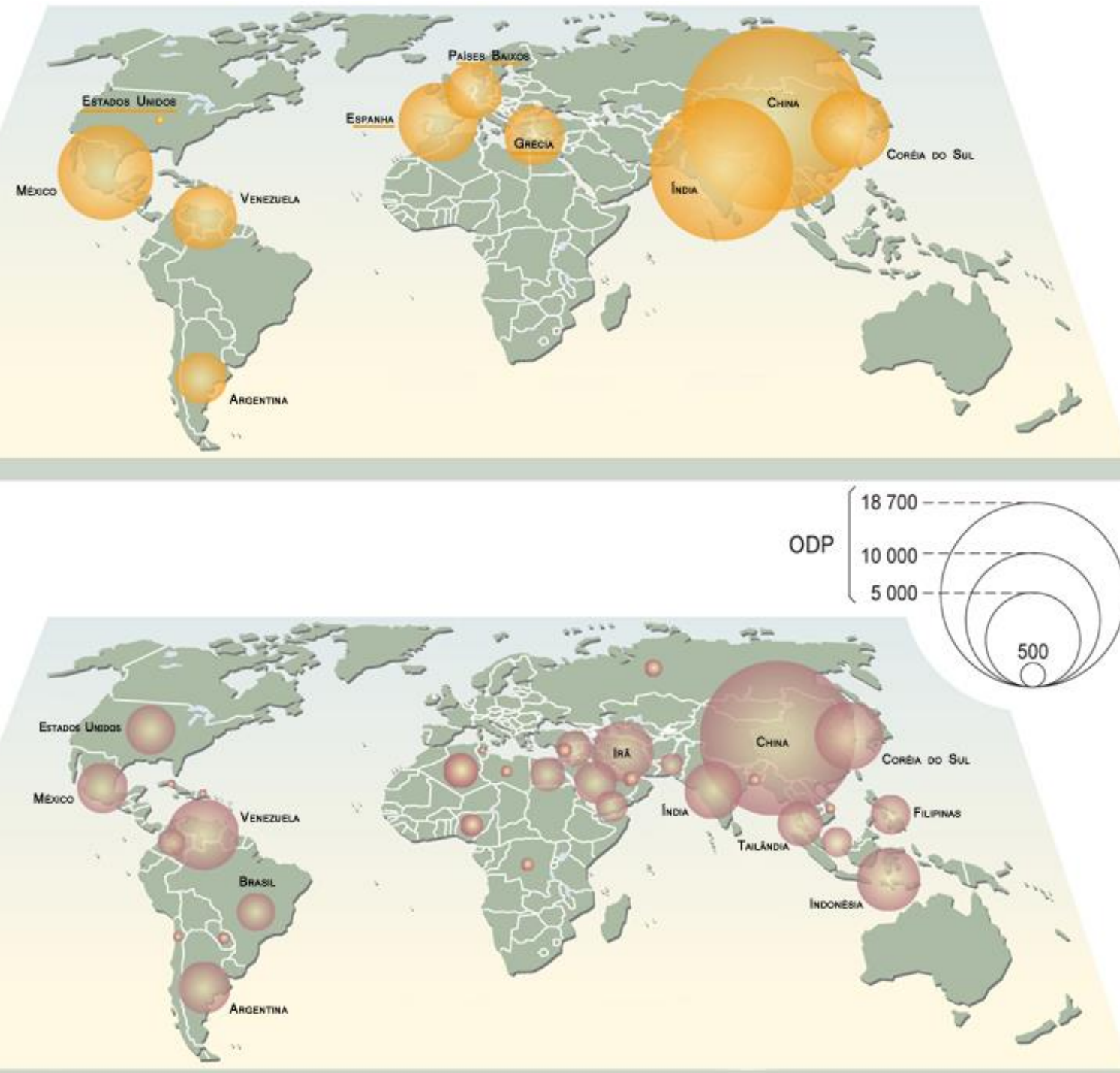

Fig.4.4.2: Acima: mapa dos produtores mundiais de CFC. Os nomes sublinhados são dos países fora do artigo 5o que ainda estão autorizados a produzir CFCs para exportação para os países em desenvolvimento para suprirem as suas "necessidades básicas internas", entre eles, os EUA. Abaixo: mapa dos países consumidores de CFCs. Os países que relataram um consumo menor que 200 toneladas ODP não estão representados. Os valores da escala ODP são em toneladas, multiplicados pelo potencial do gás considerado "depletor" de ozônio. Os dados foram reportados pelo Secretariado do Ozônio das Partes do Protocolo de Montreal (Fonte: PNUD, 2005).

Nestes termos, como as patentes agora só duram cerca de 25 anos, a burocracia enraizada eternamente nos países já trata de incriminar os HCFCs, onde alegaram que eles também são "danosos ao ozônio" e ainda por cima causam "aquecimento global". As indústrias químicas já planejaram a sua substituição, utilizando os preceitos do Protocolo de Montreal, e pretendem garantir que esta será a definitiva. É claro que as estimativas de preço para o novo produto já estão alcançando a cifra de US\$128,00 o quilograma, 
exigindo novamente a substituição de todos os equipamentos e ainda mais, todas as praças industriais, que haviam sido mudadas dos gases perigosos e explosivos para os CFCs, depois dos CFCs para os HCFCs e HFCs e agora, novamente para...? Não, não parece ser para os novos gases da família dos HFCs. Ao que se verificou, muitas indústrias, principalmente na Inglaterra, estão voltando para os gases tóxicos e explosivos, pois estes são naturais ou derivados destes e não pagam patentes. Se fitar um olhar mais cuidadoso na embalagem de seu desodorante do tipo spray, verificar-se-á que o mesmo agora possui butano ou propano na sua constituição. Isto já ocorre no Brasil.

Aliás, no Brasil, país que registra a terceira posição mundial em que mais se reduziu o uso dos CFCs, a normativa do CONAMA 267 determinou o recolhimento dos CFCs para armazenagem e reciclagem, com pessoal capacitado para o trabalho em dez estados brasileiros, com três centrais de regeneração em São Paulo e Rio de Janeiro. Há 739 máquinas recolhedoras e 335 máquinas recicladoras de CFCs. Seja lá o que forem estas afirmações, elas soam demasiadamente esquisitas. Todas estas iniciativas consomem dinheiro público e são fiscalizadas pelo setor PNUD Brasil, com um assessor técnico do Protocolo de Montreal, um cargo burocrata de gerente da "camada de ozônio" (ou xerife) dentro do IBAMA. Tal cargo é exercido por Anderson Moreira do Vale Alves e no próprio sítio da Internet do PNUD Brasil, ele explica que as unidades de reciclagem são centros de regeneração que recebem os gases contaminados e os tratam para que eles possam voltar ao mercado. Eles são capazes de reciclar o CFC-12, chamado de nocivo à "camada de ozônio", para que eles fiquem limpos e sejam utilizados novamente. Se o leitor achou a atitude altamente suspeita, não foi por menos. Consultando especialistas em refrigeração, a tal contaminação nada mais seria que, ao ficar líquido dentro do compressor, ele pode apresentar uma pequena contaminação de óleo lubrificante da própria máquina do compressor, em nada refletindo ao próprio gás. Desta forma, não é o óleo de máquina o vilão do assunto e o tal processo nada mais fez do que limpar o CFC dele, mantendo-o como o mesmo gás CFC-12 (Freon-12®). Com as suas próprias palavras, Alves afirma: 


\begin{abstract}
Esse equipamento permite a filtragem do fluido, separando o material nocivo [que seria o óleo de máquina] e purificando o gás, que volta a ser limpo. Isso possibilita seu uso com segurança e o mesmo desempenho. Os gases reciclados continuam com potencial de 'destruição' do ozônio ou de 'aquecimento global', mas terão um ciclo de vida maior em uma estratégia de contenção, para evitar que os gases sejam liberados na atmosfera". (PNUD Brasil, 2010)
\end{abstract}

Vejamos os pontos: "(...) o gás volta a ser limpo (...)", significou que permanece sendo o mesmo gás; “(...) possibilita seu uso com segurança e o mesmo desempenho (...)", significou que será utilizado da mesma maneira nos equipamentos, sem nenhuma mudança química; (...) os gases reciclados continuam com potencial de 'destruição' do ozônio ou aquecimento global (...)", significou que continuam de novo, sendo os mesmos gases, e o processo de nada adiantou; "(...) um ciclo de vida maior em uma estratégia de contenção (...)", significou que serão aplicados aos novos equipamentos, mesmo que estes não sejam mais desenhados para recebê-los. Se notarmos bem o texto, venderam literalmente uma mentira. Era de se esperar que os gases passassem por algum processo que os converteria em hidrofluorclorados ou coisa do gênero, mas nada disto ocorre. $O$ que se criou foi absolutamente uma burocracia e um processo tirânico de se confiscar os gases e reutilizá-los da mesma forma. Em outras palavras, estes gases já eram dificilmente descartados na atmosfera e tais processos já possuíam sistemas de contenção. Notou-se então, de que nada isto serviu a não ser criar este mercado de reciclagem e de certificação. Provavelmente os gases que estão aí devem ser os mesmos de sempre, pelas próprias palavras do burocrata brasileiro garantidor de que o Protocolo de Montreal seja sempre cumprido à risca.

Ao se consultar a literatura de 20 anos atrás quando se começou a cogitar a implementação destes dispositivos de reciclagem de CFCs, nove das 13 indústrias químicas fornecedoras dos CFCs estavam começando o desenvolvimento de tais máquinas. Nos dias atuais, tais processos já foram implementados, mas a questão sobre a qualidade dos gases reciclados continua em voga, pois qualquer filamento metálico, por mínimo que seja, ou resíduo de óleo ou outros gases, que normalmente contaminam o processo, são suficientes para por em risco o funcionamento dos equipamentos de refrigeração, principalmente no que tange a sua vida útil. Decerto que é o mesmo que se faz hoje em dia com cartuchos de impressoras reciclados. Sabe-se que ele pode 
funcionar ou não: é um risco que o consumidor aceita. O mesmo se aplica aos CFCs reciclados, que certamente abreviam a vida dos equipamentos, principalmente devido à corrosão, pela contaminação por água nos circuitos da tubulação do compressor (MADURO e SCHAUERHAMMER, 1992).

\subsection{Após 25 Anos: Nova Substituição}

Para os HCFCs e HFCs, a história já se aponta para o mesmo caminho. Segundo os próprios fabricantes, Os HFCs sozinhos são considerados 14 mil vezes mais "perigosos" que o dióxido de carbono $\left(\mathrm{CO}_{2}\right)$, foco dos combates internacionais para controlar as mudanças climáticas, e as emissões destes gases crescem à taxa de $8 \%$ ao ano, segundo agências da ONU. "Isto representa um futuro campo potencial de ação no âmbito do desafio das mudanças climáticas globais", ressaltou, em um comunicado, o diretor do Programa das Nações Unidas para o Meio Ambiente (PNUMA), Achim Steiner, outro alemão naturalizado brasileiro.

O terrorismo sobre este assunto já começou. Pesquisas tem sido realizadas no Brasil, como na Escola Politécnica da USP, onde outros gases de eficiência mais baixa, como os R-407C (mistura zeotrópica) e o R-410A (mistura quase-azeotrópica) surgem em substituição ao HCFC 22, tentando criar tecnologia e procedimentos de refrigeração alternativos, baseados em um benefício ecológico totalmente duvidoso (FIORELLI, 2000).

A partir de agora, de 2013 a 2030, os países em desenvolvimento estão programados para fazer uma segunda transição sob o chicote do Protocolo de Montreal, passando a eliminar os HCFCs e substituí-los pelos HFCs e supostamente por uma outra família de gases ainda não declarados. Contudo os EUA desejam que a Índia salte diretamente para os gases mais avançados, denominados de "menos impactantes", mas que utilizam tecnologias caras e patenteadas, ignorando assim, a fase dos HFCs. Uma das alternativas que está sendo proposta é produzida em conjunto pela Du Pont e Honeywell, duas multinacionais estadunidenses, e o outra, pela empresa japonesa Daiichi Sankyo Company Limited. Como o mercado indiano apresenta um enorme potencial, dado o seu crescimento e o tamanho da população, as empresas fornecedoras dos gases refrigerantes têm grande interesse. 
Recusando-se a pagar o preço para a mesma transição de tecnologia nos países mais pobres, os acordos do Protocolo de Montreal garantiram à Índia e outras economias emergentes, o trânsito aos HCFCs, cujo índice ODP (ozônio) é baixo, mas seu índice GWP (AGA) é alto (lembrando que ambos índices são absurdos). Havia grandes ganhos financeiros para os países industrializados, tanto pela sua produção, quanto pelo pagamento das patentes dos HCFCs, ou seja, uma cobrança dupla.

A contrapartida utilizada pelas nações em desenvolvimento, pelo menos as que ousam desafiar o Protocolo de Montreal, foi contra-argumentar com as próprias afirmações da UNEP e dos Grupos de Trabalho das Nações Unidas sobre Mudança do Clima. Se os novos HFCs possuem OPD zero, mas possuem alto índice GWP, então os custos de sua substituição deveriam ser arcados pelos países desenvolvidos e não os em desenvolvimento. Contudo, o lucro dos países ricos produtores vem justamente da detenção das tecnologias proprietárias que estão envolvidas, mas que não são cobertas de forma abrangente pelo Protocolo de Montreal. Em outras palavras, tal tratado torna-se uma chancela para lucros certos, sem riscos aos produtores e detentores das patentes. De certo, tal tratado não tem um mecanismo para cobrir os custos de transição, que serão sempre pagos pelo consumidor no país em desenvolvimento.

A Índia, precavendo-se da nova armadilha, alegou que nem mesmo com a opção por um longo período de transição e de uma fórmula de partilha de custos, conseguiria cobrir os investimentos que teria que fazer. Investimentos estes que seriam muito mais bem empregados em saneamento básico e agricultura do que na falácia dos gases refrigerantes.

A nova transição direta que os EUA e outros países desenvolvidos tentam realizar, serve de estratégia para ganhar (ou lucrar) com as "mudanças climáticas" e seu mercado de carbono sobre os subdesenvolvidos. No mundo hipotético dos "aquecimentistas", os gases refrigerantes possuem curta duração na atmosfera e contribuiriam muito pouco no primeiro momento, em "aquecer a Terra", quando relacionados ao dióxido de carbono. Como alegam que as emissões destes gases estão crescendo a um ritmo acelerado e que eles têm muito mais impacto climático por unidade do que o dióxido de carbono, se a troca ocorrer em tempo mais curto, tais países desenvolvidos ainda poderiam lucrar com 
créditos de carbono e demorar mais tempo em realizar suas reduções em dióxido de carbono.

No que tange aos EUA, eles pressionam para que os subdesenvolvidos passem por uma curta fase inicial de mudança para os HFCs, ao invés dos EUA se concentrarem em reduzir suas emissões de $\mathrm{CO}_{2}$. A Índia afirma que os EUA têm a chance de passar o problema da suposta ação de combate ao clima para as economias emergentes, inclusive conseguindo se firmar como um líder global sobre a questão.

Em 2012, a China e os EUA assinaram um acordo para eliminar inclusive os HFCs, utilizando mecanismos financeiros do Protocolo de Montreal, mas representando-os pela Convenção do Clima da ONU. Assim, os EUA têm exigido que a Índia realize negociações multilaterais no mesmo modo do protocolo, contudo, as autoridades indianas têm notado que as empresas de refrigeração chinesas estão em um nível tecnológico e operacional diferente. Também ressaltaram que não foi porque a China assinou um tratado que a Índia também deveria fazê-lo. Informaram que não encontraram nenhuma vantagem em se trabalhar em uma base bilateral sobre o assunto, se o único objetivo do governo dos EUA é empurrar a questão para o âmbito do Protocolo de Montreal. A polêmica com a Índia continua e pelo menos eles estão se posicionando sobre o assunto, enquanto que 0 Brasil já se arriou ao protocolo, seguindo-o à risca, em detrimento do seu povo e empreendimentos (THE INDU, 2013).

Nestes termos, exatamente como os CFCs foram "eliminados" (se é que foram), os HCFCs e HFCs já estão listados como vilões e sua substituição deve ser levada à cabo completamente até 2040 e custará ao Brasil, 33 milhões de dólares, os quais as cifras totais devem chegar a 2 bilhões de dólares. Neste contexto, o Ministério do Meio Ambiente brasileiro já se preparou para apresentar o documento para solicitar a verba ao fundo multilateral que foi também criado pelo Protocolo de Montreal, com a finalidade de se trocar os gases, já previsto anteriormente. Deve-se ressaltar que assim, cria-se mais uma enorme dívida, paga com dinheiro público. Tal documento foi elaborado em 16 de setembro de 2010, data estipulada pela ONU para marcar o Dia Internacional de Proteção à "Camada de Ozônio" (algo que não existe). Pela coordenadora da Secretaria de "Mudanças Climáticas" e Qualidade Ambiental (SMCQ), Magna Luduvice, já existiam no mercado as "alternativas" para a substituição gradativa destes gases por substâncias que 
não atacariam a "camada de ozônio". Notemos que, com a exposição maciça da fraude do ozônio, as coisas tem tomado um rumo de mudança em silêncio. Só se alardeia o terror e que medidas estão em andamento, mas não o que se realiza.

De fato, o próprio governo brasileiro já admite que haverá uma mudança enorme na cadeia produtiva, a qual atende milhões de consumidores. Isto vai exigir mais uma vez medidas governamentais e pesados investimentos privados. $O$ programa brasileiro quis estipular que em 2012 não se aumentasse o uso mais dos HCFCs e, em 2015, na sua primeira fase de redução até a completa eliminação, 400 toneladas devem deixar de ser usadas no setor de espumas, dito como o mais crítico para o enfrentamento do "problema" (já podemos prognosticar os preços dos colchões na própria estratosfera, em futuro bem próximo). Os números estipulados pelo próprio governo indicam 155,6 toneladas por meio de projetos de conversão (provavelmente mais uma trapaça "recicladora" como descrita anteriormente), 201 toneladas eliminando o uso da substância na fabricação de novos aparelhos de refrigeração doméstica e 50 toneladas no setor de manutenção destes equipamentos de refrigeração, elencando ao povo brasileiro mais um ônus. Até 2020, o governo ainda pretende eliminar 35\% do seu uso e em 2025 chegar a $67,5 \%$. Para 2030, pretende-se que $97,5 \%$ já esteja eliminado e finalmente, em 2040 , seu completo banimento.

\subsection{Precisamos de Ultravioleta B para Manter Nossa Saúde}

Notou-se que o próprio governo admite que os HCFCs tiveram seu uso regulamentado pelo Protocolo de Montreal como uma etapa de transição, até que tais gases sejam completamente banidos da fabricação de geladeiras, congeladores e condicionadores de ar. Também continuam exaltando as mentiras da "destruição da camada de ozônio" e a incidência de radiação ultravioleta que por sua vez, causa câncer de pele. Evoca-se o tempo todo o medo.

Desta forma, ainda temos uma discussão final interessante, pois a mundo enfatizou o grande problema com a radiação ultravioleta, sem dividir e explanar claramente as atribuições de cada faixa. Centenas de trabalhos se concentraram em difamar não só os CFCs, mas a radiação UV B, em experimentos laboratoriais. Notemos que o paradoxo 
biológico maior é que a radiação UV A não é barrada por nenhuma substância efetivamente e é exatamente esta que traz câncer para a pele. Já a radiação UV B, que é dosada pelo ozônio, é necessária para os seres humanos, pois é através de sua incidência que se fixa o cálcio nos ossos, com a sintetização na camada gordurosa da pele das pré-vitaminas $\mathrm{D}$. Em outras palavras, nunca houve uma proteção natural para a radiação que é maléfica a não ser a que sempre foi utilizada por todos os homens e boa parte dos seres vivos durante as eras: esconder-se do Sol nos horários de pico, se tiver que ficar lá por horas. Mas curiosamente, também deve-se ressaltar que para doses medicinais, o correto seria exatamente receber o banho de Sol por volta do meio-dia solar, pois 20 minutos bastam para a dose perfeita de radiação UV B, expondo-se pouco tempo para a radiação UV A, enquanto que para os horários recomendados do início e fim da tarde, o indivíduo tem que passar mais de uma hora exposto às duas radiações ultravioleta. Como a da banda A já apresenta seu máximo logo ao nascer do Sol, e como necessita-se de maior tempo de exposição para se atingir a dose diária da banda $\mathrm{B}$, de fato, são nos períodos do início da manhã e no final da tarde que, por exposição temporal maior à banda $A$, tem-se um malefício maior (FERREYRA, 2006). A única coisa que se concorda com estes horários é que a radiação solar é menor e cresce até o pico do meiodia, invertendo para o período da tarde, mas apenas isto. As doses de radiação UV A são altas desde quase o nascer do Sol e assim permanecem quase até o seu ocaso (Fig.4.6.1). Desta forma, não se aumentou o número de casos de câncer de pele por causa do "problema com o ozônio", mas porque as pessoas, achando-se protegidas por protetores solares, dos quais a maioria não protege nada, principalmente da faixa UV A, passaram a se expor mais nos horários indevidos e sem roupas. Portanto, o problema não foi físico-químico da "camada de ozônio", mas sim uma mudança cultural de atitude. 


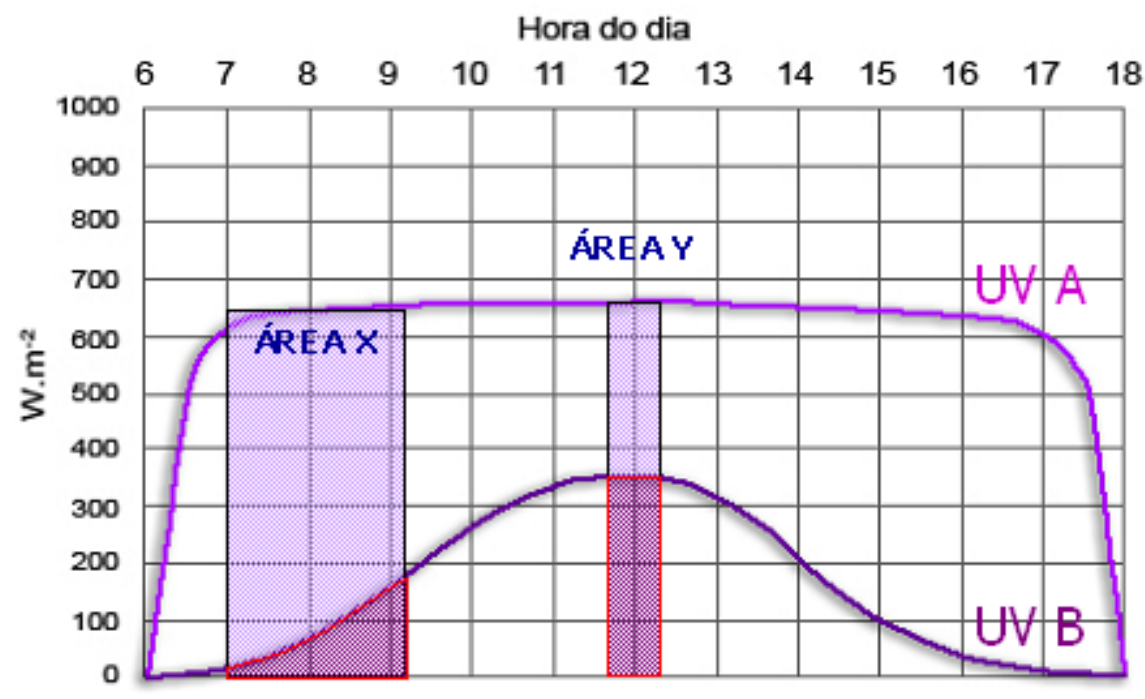

Fig.4.6.1: Gráfico das curvas de incidência das radiações UV A e UV B na superfície de uma placa plana horizontal. A radiação UV A, por ter um padrão de onda semelhante ao da luz visível, chega ao máximo logo após o nascer do Sol. A radiação UV B só consegue atingir seu pico de incidência na superfície ao meio-dia solar, pois participa de interações com o ozônio. Isto ocorre por geometria, pois a radiação UV B tem que passar por uma espessura maior da atmosfera no nascer e ocaso solares, aumentando a interação do ozônio. Assim, sabendo-se que a radiação UV A é nociva e a UV B é necessária para produzir a prévitamina $D$, a dose medicinal de UV B (área vermelha) deve ser recebida entre $11 \mathrm{~h} 50$ até $12 \mathrm{~h} 10$, diminuindo a exposição (área X > área Y) ao UV A (Fonte: adaptado por FELICIO de FERREYRA, 2006, p.81).

\section{CONCLUSÃO}

Neste segundo volume pretendeu-se demonstrar os fatores políticos e econômicos de uma intrincada rede de relações internacionais, dentro do universo de interesses da Geopolítica. Demonstrou-se como estes aspectos giram ao redor dos fatores econômicos e a riqueza produzida, bem como as facetas de poder de um tratado que se mantém celebrado graças ao medo, tanto de um problema inexistente e criado da incidência da radiação UV B, quanto de um outro muito mais poderoso e tangível, que são as sanções econômicas, as quais futuramente, com a questão do "aquecimento global" tenderão a se transformar em atos belicosos.

Nada mais a se declarar ao fato de tudo ser uma armação para criar a primeira burocracia internacional draconiana, que controlou e permanece controlando o sistema de refrigeração mundial, denegrindo a imagem dos CFCs, mesmo ao se verificar que muitos dos mesmos têm origens naturais. O cloro na atmosfera possui diversas fontes e a humana é a mais insignificante de todas. De fato, só em se observar algumas das 
substâncias que são lançadas na atmosfera pelo pólo Petroquímico de Camaçari, Bahia, cujos limites são estipulados pelo CONAMA, dada a sua toxidade, já deixam suspeitas de como apenas o cloro dos CFCs e semelhantes poderiam ser o vilão de uma coisa que não existe, a tal "camada de ozônio". A Tabela 5.1 apresentou algumas destas 38 substâncias que são normatizadas, as quais as emissões têm limites para lançamento para a atmosfera, estipulados pela legislação, por serem tratadas como poluentes. $\mathrm{Na}$ listagem da tabela, apresentou-se 19 delas (50\%) que geralmente ultrapassam os tais limites. Notou-se que o cloro é um dos elementos de maior presença e de fato, nenhum destes compostos sofreu algum tipo de sanção por destruir a tal camada, até que o Protocolo de Montreal se sinta disposto a atacá-los, desde que, é claro, as empresas de químicos já tenham um substituto (UEHARA et al., 1998).

Tabela 5.1: Compostos Químicos Cujas Emissões são Controladas no Pólo Petroquímico de Camaçari, Bahia - Brasil e que Geralmente Passam os Valores Estipulados.

\begin{tabular}{|l|l|}
\hline \hline \multicolumn{1}{|c|}{ Composto } & \multicolumn{1}{c|}{ Composto } \\
\hline Cloreto de Metileno & Estireno \\
\hline 1,2 Dicloroetano & Clorometano \\
\hline 1,2 Diclorobenzeno & Clorofórmio \\
\hline 1,4 Diclorobenzeno & Triclorofluormetano \\
\hline Tolueno & $1,1,2$ Triclorotrifluormetano \\
\hline Etilbenzeno & Tetracloreto de Carbono \\
\hline Benzeno & $1,3,5$ Trimetilbenzeno \\
\hline Cloreto de Vinila & $1,2,4$ Triclorobenzeno \\
\hline Diclorotetrafluoretano & $1,1,2,2$ Tetracloroetano \\
\hline & $\mathrm{m}$-p-Xilenos \\
\hline \hline
\end{tabular}

Assim, notou-se que incriminar os CFCs e agora os HCFCs, novamente não correspondem com a realidade da anomalia do ozônio, nem na sua mais tênue forma, sobre o Ártico, e nem na sua mais vigorosa aparição, quando ocorre sobre a Antártida. Resumindo, observamos ao longo desta compilação que: 
1 - A Teoria do Isolamento Antártico foi corroborada, onde o "Vórtice Polar Antártico" apresenta uma forma dada pelas correntes de jato em altitude, as quais isolam o ar da alta troposfera e baixa estratosfera, onde se localiza a ozonosfera;

2 - O próprio ozônio se auto-destrói, ao se chocar com outra molécula idêntica, em ambiente de alta probabilidade de encontro, em pressão atmosférica extremamente baixa, da ordem de 50 a $10 \mathrm{mb}$;

3 - A não perpetuação do processo de rápido intercâmbio entre oxigênio molecular $\left(\mathrm{O}_{2}\right)$ e sua transição para ozônio $\left(\mathrm{O}_{3}\right)$ devido a ausência de luz solar durante o inverno, consequentemente, ausência de radiação ultravioleta;

4 - A hipótese de depleção antrópica apresentada indica impossibilidade de reação com cloro em temperaturas estratosféricas extremamente baixas, na saída do inverno, como o sugerido abaixo de $-78,0^{\circ} \mathrm{C}$ ou menos;

5 - Presença de radiação infravermelha durante o inverno, em uma faixa expressiva da baixa e média estratosfera, dada a geometria de incidência de luz e pelas propriedades ópticas da atmosfera, permitem temperaturas elevadas apenas na parte periférica do "vórtice polar";

6 - Impossibilidade novamente da depleção de origem antrópica, quando as temperaturas da estratosfera se elevam consideravelmente, somente com a volta do dia polar e incidência de luz;

7 - Todas as outras fontes de cloro e gases de interferência são naturais e superam os CFCs humanos escalarmente.

É importante ainda registrar o absurdo jogo realizado com os índices de "potencialidade" ODP (relativo ao "dano" realizado ao ozônio) e o GWP (relativo ao "dano" realizado ao clima). Os gases, em geral, ora apresentam valores elevados de ODP, mas valores baixos de GWP e vice-versa. Isto impôs aos países subdesenvolvidos um esquema de manipulação na qual, em qualquer uma das situações, eles sairão perdendo. Em se tratando dos gases refrigerantes, o uso do índice GWP é completamente extorsivo, tendo em vista que é claro que eles têm um grande poder de absorção de radiação: foram projetados para isto, com a finalidade de aumentar a eficiência do processo de refrigeração. Contudo esta eficiência só é válida em ambiente fechado, pressurizado pelo 
compressor do sistema, e não na atmosfera livre, onde terá um padrão semelhante aos gases livres.

Nestes termos, após tudo que foi elencado, a hipótese da depleção do ozônio pelo cloro gerado pelos CFCs não passou de uma distorção do método científico consagrado, onde os fatores listados rechaçam completamente a hipótese e portanto, ela deveria ser banida e todos os protocolos e ações, encerradas. Mas é claro que o poder, o dinheiro, os oligopólios e os empregos de muitos burocratas e pesquisadores deixariam de existir. Assim sendo, os gases CFCs, por tudo que foi apresentado nestes dois volumes, deveriam ser declarados patrimônio da humanidade, dado o enorme número de seus benefícios e por sua estabilidade em relação ao meio ambiente.

\section{HOMENAGEM}

O segundo volume do artigo é dedicado à memória de Lewis du Pont Smith (1957-2011), professor, organizador político, filantropo e um dos herdeiros da Du Pont Corporation. Denunciou, desde o início, todas as empresas químicas pela realização de bilhões de dólares em lucros especulativos, em detrimento da vida de milhões de pessoas, promovendo o que ele sabia ser uma fraude científica e ambiental. Constantemente era rotulado como louco por membros familiares. Morreu aos 54 anos de câncer no pâncreas.

\section{REFERÊNCIAS}

FELICIO, R. A.; ONÇA, D.S. Os mitos sobre o ozônio: um resgate das origens da discussão - I. In.: Periódico Eletrônico Fórum Ambiental da Alta Paulista. Vol. 8, №8, 2012.

FERREYRA, E. El fraude del ozonio. In: Ecologia: mitos y fraudes, FAEC, México, Cap. 2, 2006. 
FIORELLI, F. A. S., Análise do escoamento de fluidos refrigerantes alternativos ao HCFC22 em tubos capilares adiabáticos. Tese de Doutorado. Escola Politécnica USP, 2000.

KAMINSKI, D. W. 1988. Refrigeration and Worldwide Food Economy. Apresentação realizada na Conferência Internacional de Refrigeração do Instituto Internacional de Refrigeração, Paris, França.

LINO, G. L., CARRASCO, L., PALACIOS, S., COSTA, N., 2007. Fabricando uma "emergência global". A Fraude do Aquecimento Global. Ed. Especial março/2007, 24pp.

MADURO, R. A. e SCHAUERHAMMER, R. The holes in the ozone scare: the cientific evidence that the sky isn't falling. $21^{\text {st }}$ Century Science Associates, Washington, D.C. EUA, 1992.

MANNEY, G. L., SANTEE, M. L., REX, M., LIVESEY, N. J., PITTS, M. C., VEEFKIND, P. e outros 23 autores., 2011. Unprecedented artctic ozone loss in 2011. Nature Vol. 478, no-10556 10.1038, pp.469-477, 2011.

MEYER, N. The Day After. Metro Goldwyn Mayer, Longa Metragem Televisivo, 1983.

SAGAN, C. Bilhões e bilhões: reflexões sobre vida e morte na virada do milênio. Ballantine Books, Nova York, EUA, 1998.

UEHARA, S. T.; FELICIO, R. A. Condições atmosféricas no pólo petroquímico de Camaçari. EIA - RIMA, Cetrel, 50pp., 1998.

Sites Acessados em setembro de 2013:

http://www.chemetron.com/utcfs/ws-5230/Assets/Chemetron_Halon1301_02092009.pdf http://www.usp.br/imprensa/?tag=jose-goldemberg

http://ozone.unep.org/new_site/en/treaty_ratification_status.php?treaty_id=\&country_id=\&s rchcrit=1\&input=Display\&not $=1$

http://www.thehindu.com/news/national/the-business-of-climatechange/article5117582.ece

http://amigosdanatureza.org.br/publicacoes/index.php/forum_ambiental/article/view/340

Agradecimento: Luciana Gerez Campos que realizou um trabalho de recuperação em uma das figuras. 